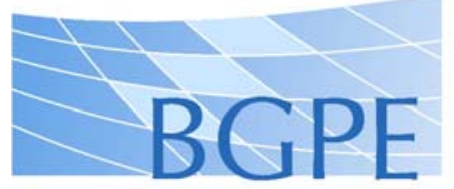

Bavarian Graduate Program in Economics

BGPE Discussion Paper

No. 140

\title{
The effects of smoking bans on self- assessed health: evidence from Germany
}

\section{Daniel Kuehnle Christoph Wunder}

August 2013 
The effects of smoking bans on self-assessed health: evidence from Germany

\author{
Daniel Kuehnle \\ University of Erlangen-Nuremberg \\ Christoph Wunder \\ University of Erlangen-Nuremberg
}

August 29, 2013

\begin{abstract}
The 16 German federal states introduced smoking bans on different dates during 2007 and 2008. These bans restricted smoking in enclosed public places, particularly in restaurants and bars. This study examines the effects of smoking bans on self-assessed health. Using data from the Socio-Economic Panel (SOEP), difference-in-differences estimations provide evidence for health improvements for the population at large. Health benefits from the secondhand smokefree environment are equivalent to an increase in household income of approximately $30 \%$. Further subgroup analyses show that health improvements are largest among young non-smokers (below 30 years) whereas smokers report no or even adverse health effects in response to bans. Exploiting differences in the dates of introduction and enforcement, we find no evidence that the effects of bans depend on enforcement measures.
\end{abstract}

Keywords: smoking bans, self-assessed health, difference-in-differences

JEL Classification: D04, C23, I10

Corresponding author: Christoph Wunder, University of Erlangen-Nuremberg, Department of Economics, Lange Gasse 20, 90403 Nuremberg, Germany. Tel.: +49 9115302 260; Fax: +49 9115302 178. Email: christoph.wunder@fau.de

Acknowledgements: We thank the participants of the Understanding Society Research Conference 2013 for helpful comments. 


\section{Introduction}

Passive smoking represents a significant public health issue and cause of mortality, as an estimated 600,000 people die each year from the exposure to secondhand smoke (Öberg et al. 2011). Indeed, numerous medical studies conclusively demonstrate that even the shortest exposure to secondhand smoke negatively affects health (for an overview, see, DHHS 2006). Over the past ten years, governments in many countries have responded by implementing policies aimed at reducing the exposure to secondhand smoke and at promoting public awareness about the dangers of smoking (WHO 2013). As one legislative measure, governments introduced smoking bans to restrict smoking in public areas, particularly in restaurants and bars.

While it seems straightforward to expect that smoking bans produce positive health outcomes, negative externalities might also exist. For example, Adda and Cornaglia (2010) show that the exposure to secondhand smoke at home increased following the introduction of antismoking policies in US states. Since smokers shifted smoking from public to private places, non-smokers, and particularly young children, experienced higher exposure to secondhand smoke. Moreover, restricted opportunities for smoking may also negatively affect smokers because earliest smoking withdrawal symptoms occur within 30 minutes of abstinence (Hendricks et al. 2006). In this context, Origo and Lucifora (2010) provide empirical evidence for increased levels of mental distress among smokers due to bans in European workplaces.

Despite the ambiguous effects that smoking bans may generate for different subgroups, research to date has tended to focus on average population effects. Furthermore, most studies on smoking bans were carried out for the US (for an overview, see, e.g., Hahn 2010). In consequence, far too little attention has been paid to potentially heterogeneous effects, and data on other countries are underexploited. 
This study investigates the causal effect of smoking bans on self-assessed health (SAH) for various subgroups using data from the German Socio-Economic Panel (SOEP). We make the following contributions to the literature. First, we extend the literature that has focused so far on objective health outcomes, such as cardiovascular diseases or heart attacks (Hahn 2010), by analysing SAH as an alternative indicator of health. SAH was used before only by Wildman and Hollingsworth (2013) to evaluate the Scottish smoking ban. However, SAH lends itself ideally to the evaluation of smoking bans because it correlates highly with health service usage, specific health conditions, mortality and recovery from illness, even when objective health indicators and other relevant variables are controlled for (Idler and Benyamini 1997, Contoyannis et al. 2004, Bowling 2005, Frijters et al. 2005). Since SAH may respond more quickly to changes in individuals' health and health-related environmental conditions than objective health indicators, SAH may furthermore serve as a leading indicator for potential long-term health outcomes that are unlikely to be captured by objective indicators, such as short-term mortality and hospitalisation rates (Shetty et al. 2009).

Second, we contribute to the literature by providing evidence on heterogeneous effects for different population subgroups. While previous research tended to focus on the consequences of smoking bans either for the entire population of for the subgroup of smokers, this study exploits information on $\mathrm{SAH}$, which is available for all survey respondents, to present additional evidence for subgroups by gender, age, and smoking status.

Third, this study extends the international literature on the effects of anti-smoking policies by providing first evidence on the causal effect of smoking bans on SAH in Germany, a country that displays relatively high smoking rates (about 30\%) compared to other European countries (Storr et al. 2010). 
Fourth, we investigate for the first time the question of whether health effects of smoking bans depend on enforcement measures. No other study has addressed this particularly policyrelevant to the best of our knowledge before. Here, the pattern of implementation of smoking bans in Germany allows us to disentangle the separate effects of introduction and enforcement.

We estimate the causal effect of smoking bans on SAH using a difference-in-differences approach that exploits the staggered introduction of smoking bans on the state-level in Germany. We find significant health improvements following the implementation of smoking bans for the population at large. Subgroup analyses provide evidence for heterogeneous responses: while non-smokers exhibit significant health improvements, smokers report no or even adverse health effects, supporting the hypothesis that reduced smoking opportunities may negatively impact on smokers' health. We find particularly large effects for young non-smokers (i.e. aged less than 30) who are likely to benefit from less exposure to secondhand smoke in bars, clubs and restaurants. Exploiting further temporal variation in the dates of enforcement, we show that the health effects do not depend on enforcement measures but materialise with the legal introduction of the smoking bans. Our results are robust to alternative specifications of the time trend, the inclusion of state-specific time trends, the assumption of cardinality or ordinality of SAH, as well as a placebo reform test.

The paper is organised as follows. In Section 2, we provide the necessary background in terms of institutional details and previous literature. Sections 3 and 4 present our empirical strategy and data description, respectively. Section 5 presents and discusses the empirical results, and provides a number of sensitivity checks confirming the robustness of our results. Section 6 concludes. 


\section{Background}

In Germany, the 16 federal states introduced smoking bans on different dates during 2007 and 2008 (see Table 1). The bans aimed at reducing the exposure to secondhand smoke, which has extensively been shown to cause serious illnesses and death (WHO 2013). Although the smoking bans differ to some extent between states in terms of scope and strictness, they generally prohibit smoking in restaurants and bars as well as in other enclosed public areas, such as hospitals, theatres, museums, cinemas, concert halls, universities, and airports. Baden-Wuerttemberg, Lower Saxony, and Mecklenburg-West Pomerania were the first states to introduce bans in August 2007. By July 2008, all 16 states were covered by a smoking ban. While ten out of the 16 federal states legally enforced smoking bans when these came into effect, six federal states delayed enforcement measures to a later date. Penalties for offending smokers and bars/restaurants depend on the state and can be up to 10,000 Euros.

German smoking bans have already been the subject of a number of studies. Analysing hospital admissions due to myocardial infarctions before and after the introduction of smoking bans in Bremen and Lower Saxony, Schmucker et al. (2013) find a significant decline of admissions for non-smokers, but not for smokers. However, no study examines the effects of smoking bans on health for other federal states or Germany in total. With respect to smoking behaviour, Anger et al. (2011) find no effect of smoking bans on average. However, the study provides evidence for a decline in smoking propensity and intensity for those who regularly go out. Kvasnicka (2010) and Kvasnicka and Tauchmann (2012) find that electronic age-verification in cigarette vending machines negatively affected cigarette sales, whereas a nationwide smoking ban in federal buildings had no effect.

A concise review of the international medical literature on smoking bans can be found in Hahn (2010). Most of the studies reviewed document positive health outcomes following the 
introduction of a smoking ban. For example, Sargent et al. (2004) report a 40\% decline in acute myocardial infarction (AMI) after a local smoking ban came into effect. However, the study does not control for confounding factors or an underlying time trend. Two similar studies also report declining rates of AMIs following a smoking-ban (Bartecchi et al. 2006, Khuder et al. 2007). For Canada, Carpenter et al. (2011) show that the smoking ban lowered exposure to environment tobacco smoke (ETS) in public places but that it did not significantly reduce smoking prevalence or intensity. Due to data constraints, the study was not able to assess the effect on health outcomes, however.

Outside of the US, few studies investigates the health effects for European countries. In a recent paper, Wildman and Hollingsworth (2013) investigate the effect of the introduction of smoking-bans on SAH in Scotland. The authors find significant health improvements only for women who have never smoked. Studies from Scotland and Northern Ireland (Allwright et al. 2005, Menzies et al. 2006, Goodman et al. 2007) examine the effects of smoking bans on workers in bars and restaurants. The authors provide evidence for significant improvements in the respiratory health of non-smoking bar workers as a result of the reduced exposure to secondhand smoke. In a meta-study, Polańska et al. (2011) show that the levels of nicotine absorbed in the blood (cotinine) by workers in the hospitality sector reduced significantly after the introduction of a total smoking ban in bars.

Only little research examines the effects for different population subgroups (see, for instance, Hahn 2010). Notably, Adda and Cornaglia (2010) finds that the introduction of smokingbans in the US produced unintended negative consequences. The study shows that the level of cotinine in children increased substantially after the introduction of a smoking-ban in the US. Adams et al. (2013) examine the impact of smoke-free workplace laws on fatal heart attacks 
and find heterogeneous responses for different age groups, as the effect generally decreases with age. However, we are not aware of similar studies for Germany.

\section{Empirical strategy}

To identify the causal effect of smoking bans on SAH, we employ a difference-in-differences (DID) approach that exploits regional variation in implementation dates across German federal states. Intuitively, the DID estimate of the effect is based on the difference in the before-after change in SAH between federal states with a ban and those without a ban. The regression equation is

$$
S A H_{i s t}=\alpha \text { ban }_{\text {st }}+\gamma^{\prime} \text { state }_{s}+\boldsymbol{\delta}^{\prime} \text { time }_{t}+\boldsymbol{\beta}^{\prime} \mathbf{x}_{\text {ist }}+\varepsilon_{i s t},
$$

where $S A H$ is the self-assessed health of individual $i$ in federal state $s$ at time $t$. ban is an indicator variable that equals one if the individual lives in a state that is covered by a smoking ban at time $t$. We define the ban variable according to the introduction dates (see Table 1). The coefficient of interest, $\alpha$, measures the causal effect of smoking bans on SAH. The vector $\mathbf{x}$ contains controls for socio-economic characteristics, including age and its square, (the logarithms of) household income and household size, the number of years of education, indicator variables for marital status (married, divorced, and widowed, with single as the reference group), the presence of children below age 6 and aged 6 and older, immigrant status, and unemployment. The DID approach takes account of unobserved variables that might affect SRH on the federal state level and/or over time by controlling for state effects and time effects: state is a set of indicator variables for the German federal states and time represents the time trend. $\beta, \gamma$ and $\delta$ represent additional parameters to be estimated and $\varepsilon$ is the error term. 
We use two different specifications for the time trend in SAH. First, we employ a piecewise linear trend that allows for slopes and intercepts to vary with each wave. However, an over-parsimonious specification of the time trend may falsely attribute changes in slope or nonlinearities not captured by the model to the smoking bans (e.g., Huesch et al. 2012). To accommodate this concern, we also use a fully nonparametric model where time represents a full set of indicator variables for each day of the interview period. By not imposing any (parametric) restrictions on the functional form, this specification is the most flexible one as it nests any parametric specification of the time trend.

To examine the sensitivity of our results with respect to the common time trend, which is the key identifying assumption for the DID approach, we perform two robustness checks. First, we extend the basic specification in equation 1 by including additional state-specific linear time trends. If a common time trend exists between treated and non-treated states, the estimate of $\alpha$ should not change much by the inclusion of these variables (Angrist and Pischke 2009). Second, we estimate the effect of a placebo reform, using false introduction dates that are known to have no effect on SAH. Hence, we expect insignificant coefficients of the placebo reform while significant coefficients would cast doubt on the interpretation of $\alpha$ as a causal effect of smoking bans.

Since our research design uses repeated observations that are clustered in federal states, OLS standard errors that ignore the clustering are inconsistent (Bertrand et al. 2004). To address the clustering problem, we first compute cluster-robust standard errors. ${ }^{1}$ However, cluster-robust standard errors are valid only asymptotically and standard asymptotic tests may over-reject the null hypothesis when the number of clusters is small. Therefore, the need arises to further correct the estimated variance-covariance matrix (e.g., Donald and Lang 2007). Using Monte

\footnotetext{
${ }^{1}$ We calculate cluster-robust standard errors using the vce(cluster) option in Stata 12.
} 
Carlo simulations, Cameron et al. (2008) show that the wild cluster bootstrap-t method does especially well when the number of clusters is very small (as low as six). Although we have 16 clusters, we additionally report $p$-values for our coefficient of interest, $\alpha$, obtained from the wild cluster bootstrap-t method. ${ }^{2}$

\section{Data}

We use survey data from the German-Socio-Economic Panel (SOEP), which is a nationally representative household survey carried out annually. The main analysis covers the reform years 2007 and 2008. For a robustness check with a placebo reform, we use additional data from 2005 and 2006. The SOEP provides detailed information on the socio-economic characteristics of respondents, their health status, and, most importantly for our identification strategy, their place of residence and the interview date. Since answers to subjective survey questions may be affected by panel and learning effects (Ehrhardt et al. 2000), we drop the first three interviews of each respondent. ${ }^{3}$ To examine heterogeneous effects of smoking bans, we produce subsamples by smoking status, gender, and age. Table A1 in the appendix reports the sample sizes.

The SOEP surveys the smoking status only every second year. Hence, we use information from the pre-regulation years 2002, 2004, and 2006 to generate the smoking status. We do this for two reasons: first, we refrain from using information from 2008, as the reform could have directly affected the smoking status in 2008. Second, since some smokers only quit temporarily, the information about smoking status may be prone to measurement error resulting from on-andoff smoking. Information from multiple periods may help to distinguish more clearly between smokers and non-smokers. We therefore consider a respondent a smoker if he or she reports

\footnotetext{
${ }^{2}$ We thank Doug Miller for sharing his code, which we have modified for our purposes, on calculating p-values obtained from the wild cluster bootstrap-t method.

${ }^{3}$ Our results are generally not affected by this sample selection criterion.
} 
smoking at one of these pre-regulation interviews. ${ }^{4}$ In total, $36 \%$ of our observations are coded as smokers, $64 \%$ as non-smokers.

SAH is measured on a five-point scale ranging from 1 (very good) to 5 (bad), i.e., higher values indicate poorer health status. The variable has a mean of 2.7 and standard deviation of 0.95. Table 2 shows descriptive statistics for the whole sample and by smoking status. Nonsmokers report better subjective health than smokers, despite of potential age-related health deteriorations associated with being about eight years older on average than smokers.

Next, we graphically inspect the time trend in SAH for individuals in our sample. The DID approach rests on the key assumption of a common time trend. We provide a first descriptive assessment of the common trends assumption by investigating the trends in SAH before the reform was introduced. Figure 1 shows average values of SAH for individuals living in a state with a smoking ban in 2007 (early-implementing states) and for individuals living in a state with a smoking ban in 2008 (late-implementing states). The time trends in both early-implementing states and late-implementing states show a similar pattern and they tend to move in the same direction. Since the graphs only use information about individuals that we observe in 2007 and 2008, the continuous upward trend over the period 2003-2008 reflects the ageing of respondents.

Finally, Table 3 presents mean values of SAH by state, along with the change in the health outcome following the introduction of smoking bans. In ten out of 16 states, we find negative values for the change, indicating health improvements following the introduction of a smoking ban. These ten states cover approximately $75 \%$ of the total population. On average, we observe an improvement in SAH by 0.02 points on the five-point scale.

\footnotetext{
${ }^{4}$ In principle, one may use alternative definitions of the smoking status. For example, Wildman and Hollingsworth (2013) use an even stricter definition of non-smokers, regarding only individuals who have never smoked during the entire survey period of the British Household Panel Survey, spanning the years 1991 to 2007 , as non-smokers. We have experimented with a number of definitions and the results are qualitatively identical.
} 


\section{Empirical results}

\subsection{Average effect of smoking bans}

Table 4 presents the estimation results for the causal effect of smoking bans, $\alpha$ in equation 1 , for the entire population and for population subgroups. Each estimate is obtained from a separate regression. The columns show results by smoking status and the rows differentiate between gender and age.

The empirical evidence presented in Panel A shows that the implementation of smoking bans leads to a significant improvement in SAH for the population at large. ${ }^{5}$ The coefficient of the ban indicator is statistically significantly negative. The point estimate reveals an improvement of SAH by about 0.05 points on the five-point scale. ${ }^{6}$

To put this effect into perspective, we calculate the compensating income variation (CIV). Since secondhand smoke represents an important source of air pollution, the CIV can be regarded as a measure of the monetary equivalent of a smoke-free environment. ${ }^{7}$ The coefficient of the (logarithm of the) household income is estimated to be -0.19 , suggesting that higher income is associated with better health (Currie 2009). Therefore, the health benefits from the secondhand smoke-free environment are equivalent to an increase in household income of approximately $30 \%{ }^{8}$ Another benchmark against which to compare the effect of the smoking ban is the coefficient of the unemployment variable. Although recent research shows that unemployment does not causally affect SAH (e.g. Böckerman and Ilmakunnas 2009), we make use of the coefficient to illustrate the size of the effect of bans. The comparison of coefficients

\footnotetext{
${ }^{5}$ Column 1 in Table 5 contains the full estimation results for the entire sample.

${ }^{6}$ Due to the coding of the SAH variable, a negative coefficient reflects health improvements. See Section 4.

7 The concept of using subjective information to calculate the monetary equivalent of externalities is frequently used in studies on subjective well-being, for example to quantify the effects of air pollution (Welsch 2006).

${ }^{8}$ Calculated as $(\exp (0.05 / 0.19)-1) \cdot 100 \%$.
} 
shows that the effect of smoking bans is about one third $(-0.053 / 0.153)$ of the difference in SAH between unemployed individuals and not-unemployed individuals. In sum, both comparisons demonstrate that the smoking bans have quite substantial effects on SAH.

\subsection{Effects by smoking status, gender and age}

This subsection presents the empirical evidence on heterogeneities in relevant subgroups that are expected to respond differently to smoking bans. Although a smoke-free environment is generally expected to improve objective health outcomes on average (see Section 2), we hypothesise heterogeneous effects on SAH for non-smokers and smokers. Consistent with prior studies (Hendricks et al. 2006, Origo and Lucifora 2010), we first expect that smokers experience stress from withdrawal symptoms resulting from reduced smoking opportunities. Second, we expect health improvements for non-smokers in response to a reduction in exposure to second-hand smoke.

The empirical results in columns 2 and 3 in Table 4 provide evidence supporting these hypotheses. ${ }^{9}$ For non-smokers, the effect of the ban (-0.097) is almost twice as large as that for the entire population (-0.05) and statistically significant. For smokers, we estimate a small positive coefficient (0.03) with large p-values, indicating non-significance. However, the positive sign is consistent with the hypothesis that smoking bans impose some stress on smokers. Therefore, non-smokers benefit strongly from the smoking ban while smokers subjectively do not experience health benefits.

Next, we split the previously analysed samples by gender. The results for females and males are presented in panels B and C in Table 4, respectively. Our empirical evidence points towards gender-specific responses to the introduction of smoking bans, with stronger effects among

\footnotetext{
${ }^{9}$ Columns 2 and 3 in Table 5 show the full estimation results for non-smokers and smokers, respectively.
} 
females than males. On average, bans improve SAH for females by about 0.09 points whereas the estimate is smaller (-0.02) and statistically insignificant for males.

Taking smoking status into account, the results again show that non-smokers benefit from the smoking ban whereas smokers do not. Female non-smokers benefit particularly strongly from the ban, as reflected in the estimate (-0.12). Male non-smokers also benefit (-0.074), but the coefficient marginally misses the $10 \%$ significance level. Consistent with our first hypothesis on smoking withdrawal symptoms, we find a deteriorating effect for male smokers $(0.06)$ which, however, is estimated imprecisely and not statistically significantly different from zero.

Finally, in panels B and C in Table 4, we investigate further heterogeneities by distinguishing between three age groups that may differ in their behaviour (see Section 2) - a young group (below 30), a middle group (aged 30-49), and an aged group (50 and over). On average, we observe the strongest effects for the young group, a finding that might reflect the patterns of going-out, as the young group is expected to go out more often to bars and clubs compared to the older age groups. For females, the effects of bans decrease in absolute terms with age, ranging from -0.178 for the young group to -0.038 for the aged group. The effects for females are almost exclusively driven by female non-smokers, as the effects for female smokers are generally insignificant. For males, the effect is also strongest for the young group (-0.052), but differs clearly between smokers and non-smokers: while young male non-smokers report very large health improvements (-0.397), young smokers experience deteriorating SAH (0.270).

Comparing the coefficients in column 1 (Table 4) between men and women, we generally find that the female coefficients are larger in absolute terms than the male ones. This finding is consistent with evidence by Meurer et al. (2001) who report a high tobacco smoke sensitivity among females. Furthermore, a particularly large gender differences arise in the middle age group, where the average effect of the smoking ban is large for women (-0.111) and basically 
zero $(0.001)$ for men. It is possible that women in this age group, i.e. women in child-rearing age, may be particularly sensitive towards health risks. Indeed, a number of studies argue that women make health judgements on a broader and more inclusive set of information than men (Benyamini et al. 2000, Dowd and Todd 2011). Although these studies do not distinguish between age groups, they provide a potential explanation for the gender difference.

\subsection{Does enforcement matter?}

We now extend the empirical evidence by examining a model that distinguishes between the introduction and enforcement of smoking bans. Most federal states legally enforced their smoking bans right from the first day. However, six federal states applied enforcement measures only at a later date (see Table 1). In these states, authorities did not pursue or punish non-compliance with the law between the date of introduction and the date of enforcement.

To investigate whether the effects of bans depend on enforcement measures, we employ an extended model that exploits variation in dates of introduction and dates of enforcement. We therefore use two ban indicators, i.e. one for the date of introduction (intro) and one for the date of enforcement (enfor), instead of the single ban indicator in equation 1. The extended model is

$$
S A H_{\text {ist }}=\alpha_{1} \text { intro }_{s t}+\alpha_{2} \text { enfor }_{\text {st }}+\gamma^{\prime} \text { state }_{s}+\delta^{\prime} \text { time }_{t}+\beta^{\prime} \mathbf{x}_{\text {ist }}+\varepsilon_{i s t} .
$$

Table 6 presents the estimation results for the parameters $\alpha_{1}$ and $\alpha_{2}$. By splitting the effect of the smoking ban into two separate effects, no single effect is individually significant any more on average (column 1). Column 2, however, reveals that the introduction of smoking bans has an instantaneous positive effect on SAH of non-smokers. Approximately $90 \%$ of the health improvements for non-smokers emerge immediately with the introduction, whereas the 
enforcement of the ban produces hardly additional benefits. Although this study is unable to make inferences on the total rate of compliance, our finding is consistent with the notion that people complied with the introduction of the law, and that enforcement measures were not crucial for compliance. Indeed, this conclusion is in line with a recent study which found that Germany, alongside the US and the Netherlands, belongs to the group of countries that highly value adherence to social rules (Dragolov et al. 2013).

A different pattern emerges for smokers, though the coefficients are estimated imprecisely. Smokers first experience a deterioration with the introduction of the smoking ban, followed by an improvement with the enforcement of the smoking ban. The temporary deterioration of SAH following the introduction is almost completely offset by the improvement following the enforcement of the ban. This pattern may reflect an adaptation process among smokers who may first experience substantial stress with the introduction of the smoking ban, but learn how to deal with the restrictions over time so that their health is not affected in the long-run.

\subsection{Robustness checks}

This section provides three robustness checks validating our main empirical results by (1) estimating extended specifications for the time trend, (2) running a placebo estimation, and (3) running an ordered probit regression to relax the assumption of cardinality of SAH scores.

First, we turn to extended estimations in Table 7 to investigate the robustness of the results with respect to different specifications of the time trend. In general, all model specifications of the time trend in columns 1 to 4 estimate effects of similar magnitude, confirming that our main results are robust to the modelling of the time trend. Column 1 replicates the results from our preferred model with a piecewise linear time trend. The results in column 2 are based on a fully nonparametric model that allows for arbitrarily nonlinear time trends. The estimates are almost 
identical to that of model 1. Columns 3 and 4 extend the two previous models (models 1 and 2) with state-specific linear time trends. We find no evidence for sizeable changes compared to the restricted specifications, providing support to the assumption of common time trends in SAH among federal states.

As a second robustness check, column 5 in Table 7 reports estimates of the effect of a placebo ban. We use data for the pre-regulation years 2005 and 2006 to estimate the same model specification as for 2007 and 2008. In particular, the placebo ban exactly mirrors the staggered time pattern of the true ban, only two years earlier. In the absence of a smoking ban in the pre-regulation period, the placebo ban should have no effect on SAH. Results in column 5 show that eight out of nine effects are estimated to be small and not statistically significantly different from zero. Only the coefficient for male smokers is statistically significant at the 10 percent level. However, performing 10 significance tests at the 10 percent level, we expect to incorrectly reject one of the null hypotheses, when all null hypotheses are true. Therefore, we argue that the placebo test confirms that the changes in SAH provided earlier for the years 2007 and 2008 can indeed be causally attributed to the smoking bans.

Finally, we report an additional robustness check in which we relax the assumption underlying OLS that reported health scores are cardinal. We estimate ordered probit regressions that use the assumption of ordinality, instead. ${ }^{10}$ Overall, the results of the OLS regressions are clearly confirmed by the ordered probit regressions. In particular, we find a statistically significantly negative coefficient for the entire sample (column 1). The subgroup-specific results by smoking status indicate that the effect is driven by non-smokers (column 2), while the effect for smokers is insignificant (column 3). We conclude that the results are not affected by assuming ordinality or cardinality of SAH.

\footnotetext{
${ }^{10}$ The results are in Table A2 in the appendix.
} 


\section{Conclusion}

The exposure to secondhand smoke represents an important cause of serious illnesses and death. In recent years, legislative measure were implemented worldwide to protect the health of individuals in public places. In Germany, the 16 federal states introduced smoking bans on different dates during 2007 and 2008, prohibiting smoking not only in restaurants and bars, but also in other enclosed public areas such as hospitals, theatres, museums, cinemas, concert halls, universities, and airports.

This study uses a difference-in-differences approach to extend the international literature by providing evidence on the effect of smoking bans on SAH. The analysis of subjective data has two particular advantages: first, SAH data allow a comprehensive evaluation because they are available for all respondents. Thus, we are able to provide evidence on heterogeneous responses by estimating the effects for subgroups that are assumed to respond differently to smoking bans. Second, since SAH may serve as a leading indicator for long-term health outcomes, our study provides a first indication of potential long-term effects of smoking bans.

We find that smoking bans successfully improve SAH on average. Furthermore, our evidence provides evidence for heterogeneous effects by smoking status and age: non-smokers benefit from smoking bans while smokers do not benefit or, as in the case of young male smokers, even report health deterioration. Presumably, smokers experience stress from the reduced opportunities for nicotine intake. In general, the largest improvements were found among young non-smokers (below 30 years). The results indicate gender-specific responses, as women on average respond more strongly to the ban than men. However, the result for women is almost exclusively driven by improvements in health for non-smokers. In particular, female non-smokers in the aged 30-49 are most responsive, while males in this age group show no improvements. This finding may potentially be explained by gender-specific sensitivities regarding health, as it 
has been shown that females assess their health on a broader and more inclusive set of information than males (Benyamini et al. 2000).

Although this study has proven that smoking bans are an effective measure to improve health among non-smokers, they apparently do not reach smokers. In the light of no or even adverse effects among smokers, we recommend that countries planning to introduce smoking bans should target smokers with further health campaigns. For example, it may be useful to combine smoking bans with specific anti-smoking campaigns to motivate smoking cessation. In this way, the combination of several anti-smoking policies may push tobacco-free lifestyles to a broad social acceptance. 


\section{References}

Adams, S., Cotti, C., and Fuhrmann, D. (2013). The short-term impact of smoke-free workplace laws on fatal heart attacks. Applied Economics, 45(11):1381-1393.

Adda, J. and Cornaglia, F. (2010). The effect of bans and taxes on passive smoking. American Economic Journal: Applied Economics, 2(1):1-32.

Allwright, S., Paul, G., Greiner, B., Mullally, B. J., Pursell, L., Kelly, A., Bonner, B., D’Eath, M., McConnell, B., McLaughlin, J. P., O’Donovan, D., O'Kane, E., and Perry, I. J. (2005). Legislation for smoke-free workplaces and health of bar workers in Ireland: before and after study. BMJ, 331(7525):1117-1117.

Anger, S., Kvasnicka, M., and Siedler, T. (2011). One last puff? Public smoking bans and smoking behavior. Journal of Health Economics, 30(3):591-601.

Angrist, J. and Pischke, J. (2009). Mostly harmless econometrics. Princeton, NJ: Princeton University Press.

Bartecchi, C., Alsever, R., Nevin-Woods, C., Thomas, W., Estacio, R., Bartelson, B., and Krantz, M. (2006). Reduction in the incidence of acute myocardial infarction associated with a citywide smoking ordinance. Circulation, 114(14):1490-1496.

Benyamini, Y., Leventhal, E., and Leventhal, H. (2000). Gender differences in processing information for making self-assessments of health. Psychosomatic Medicine, 62(3):354-364.

Bertrand, M., Duflo, E., and Mullainathan, S. (2004). How much should we trust differencesin-differences estimates? The Quarterly Journal of Economics, 119(1):249-275.

Böckerman, P. and Ilmakunnas, P. (2009). Unemployment and self-assessed health: evidence from panel data. Health Economics, 18(2):161-179.

Bowling, A. (2005). Just one question: if one question works, why ask several? Journal of Epidemiology and Community Health, 59(5):342-345.

Cameron, A. C., Gelbach, J. B., and Miller, D. L. (2008). Bootstrap-based improvements for inference with clustered errors. The Review of Economics and Statistics, 90(3):414-427.

Carpenter, C., Postolek, S., and Warman, C. (2011). Public-place smoking laws and exposure to environmental tobacco smoke (ETS). American Economic Journal: Economic Policy, 3(3):35-61.

Contoyannis, P., Jones, A., and Rice, N. (2004). The dynamics of health in the British Household Panel Survey. Journal of Applied Econometrics, 19(4):473-503.

Currie, J. (2009). Healthy, wealthy, and wise: socioeconomic status, poor health in childhood, and human capital development. Journal of Economic Literature, 47(1):87-122.

DHHS (U.S. Department of Health and Human Services) (2006). The health consequences of involuntary exposure to tobacco smoke: a report of the surgeon general. Technical report, Atlanta, GA: U.S. Department of Health and Human Services, Centers for Disease Control and Prevention, Coordinating Center for Health Promotion, National Center for Chronic Disease Prevention and Health Promotion, Office on Smoking and Health. 
Donald, S. G. and Lang, K. (2007). Inference with difference-in-differences and other panel data. The Review of Economics and Statistics, 89(2):221-233.

Dowd, J. B. and Todd, M. (2011). Does self-reported health bias the measurement of health inequalities in US adults? Evidence using anchoring vignettes from the health and retirement study. The Journals of Gerontology Series B: Psychological Sciences and Social Sciences, 66(4):478-489.

Dragolov, G., Ignacz, Z., Lorenz, J., Delhey, J., and Boehnke, K. (2013). Radar gesellschaftlicher Zusammenhalt. messen was verbindet. Gesellschaftlicher Zusammenhalt im internationalen Vergleich. Bertelsmann Stiftung, Gütersloh.

Ehrhardt, J. J., Saris, W. E., and Veenhoven, R. (2000). Stability of life-satisfaction over time. Journal of Happiness Studies, 6(2):177-205.

Frijters, P., Haisken-DeNew, J., and Shields, M. (2005). The causal effect of income on health: evidence from German reunification. Journal of Health Economics, 24(5):997-1017.

Goodman, P., Agnew, M., McCaffrey, M., Paul, G., and Clancy, L. (2007). Effects of the Irish smoking ban on respiratory health of bar workers and air quality in Dublin pubs. American Journal of Respiratory and Critical Care Medicine, 175(8):840-845.

Hahn, E. J. (2010). Smokefree legislation: a review of health and economic outcomes research. American Journal of Preventive Medicine, 39(6):S66-S76.

Hendricks, P. S., Ditre, J. W., Drobes, D. J., and Brandon, T. H. (2006). The early time course of smoking withdrawal effects. Psychopharmacology, 187(3):385-396.

Huesch, M. D., Østbye, T., and Ong, M. K. (2012). Measuring the effect of policy interventions at the population level: some methodological concerns. Health Economics, 21(10):12341249 .

Idler, E. L. and Benyamini, Y. (1997). Self-rated health and mortality: a review of twenty-seven community studies. Journal of Health and Social Behavior, 37(1):21-37.

Khuder, S., Milz, S., Jordan, T., Price, J., Silvestri, K., Butler, P., et al. (2007). The impact of a smoking ban on hospital admissions for coronary heart disease. Preventive medicine, 45(1):3-8.

Kvasnicka, M. (2010). Public smoking bans, youth access laws, and cigarette sales at vending machines. Technical Report 173, Ruhr Economic Paper.

Kvasnicka, M. and Tauchmann, H. (2012). Much ado about nothing? Smoking bans and Germany's hospitality industry. Applied Economics, 44(35):4539-4551.

Menzies, D., Nair, A., Williamson, P. A., Schembri, S., Al-Khairalla, M. Z. H., Barnes, M., Fardon, T. C., McFarlane, L., Magee, G. J., and Lipworth, B. J. (2006). Respiratory symptoms, pulmonary function, and markers of inflammation among bar workers before and after a legislative ban on smoking in public places. JAMA: The Journal of the American Medical Association, 296(14):1742-1748.

Meurer, L., Layde, P., and Guse, C. (2001). Self-rated health status: a new vital sign for primary care? Wisconsin Medical Journal, 100(7):35-39. 
Öberg, M., Jaakkola, M., Woodward, A., Peruga, A., and Prüss-Ustün, A. (2011). Worldwide burden of disease from exposure to second-hand smoke: a retrospective analysis of data from 192 countries. The Lancet, 377(9760):139-146.

Origo, F. and Lucifora, C. (2010). The effect of comprehensive smoking bans in European workplaces. IZA Discussion Papers 5290, Institute for the Study of Labor (IZA).

Polańska, K., Hanke, W., and Konieczko, K. (2011). Hospitality workers' exposure to environmental tobacco smoke before and after implementation of smoking ban in public places: a review of epidemiological studies. Medycyna pracy, 62(2):211.

Sargent, R. P., Shepard, R. M., and Glantz, S. A. (2004). Reduced incidence of admissions for myocardial infarction associated with public smoking ban: before and after study. $B M J$, 328(7446):977-980.

Schmucker, J., Wienbergen, H., Seide, S., Fiehn, E., Fach, A., Würmann-Busch, B., Gohlke, H., Günther, K., Ahrens, W., and Hambrecht, R. (2013). Smoking ban in public areas is associated with a reduced incidence of hospital admissions due to ST-elevation myocardial infarctions in non-smokers. results from the BREMEN STEMI REGISTRY. European Journal of Preventive Cardiology. Online first. DOI: 10.1177/2047487313483610.

Shetty, K. D., DeLeire, T., White, C., and Bhattacharya, J. (2009). Changes in U.S. hospitalization and mortality rates following smoking bans. NBER Working Papers 14790, National Bureau of Economic Research, Inc.

Storr, C., Cheng, H., Alonso, J., Angermeyer, M., Bruffaerts, R., de Girolamo, G., de Graaf, R., Gureje, O., Karam, E., Kostyuchenko, S., et al. (2010). Smoking estimates from around the world: data from the first 17 participating countries in the world mental health survey consortium. Tobacco Control, 19(1):65-74.

Welsch, H. (2006). Environment and happiness: Valuation of air pollution using life satisfaction data. Ecological Economics, 58(4):801-813.

WHO (World Health Organization) (2013). WHO report on the global tobacco epidemic, 2013. WHO Document Production Services, Geneva.

Wildman, J. and Hollingsworth, B. (2013). Public smoking bans and self-assessed health: evidence from Great Britain. Economics Letters, 118(1):209-212. 
Figures and tables

\section{Figure 1}

Average self-rated health over time in Germany

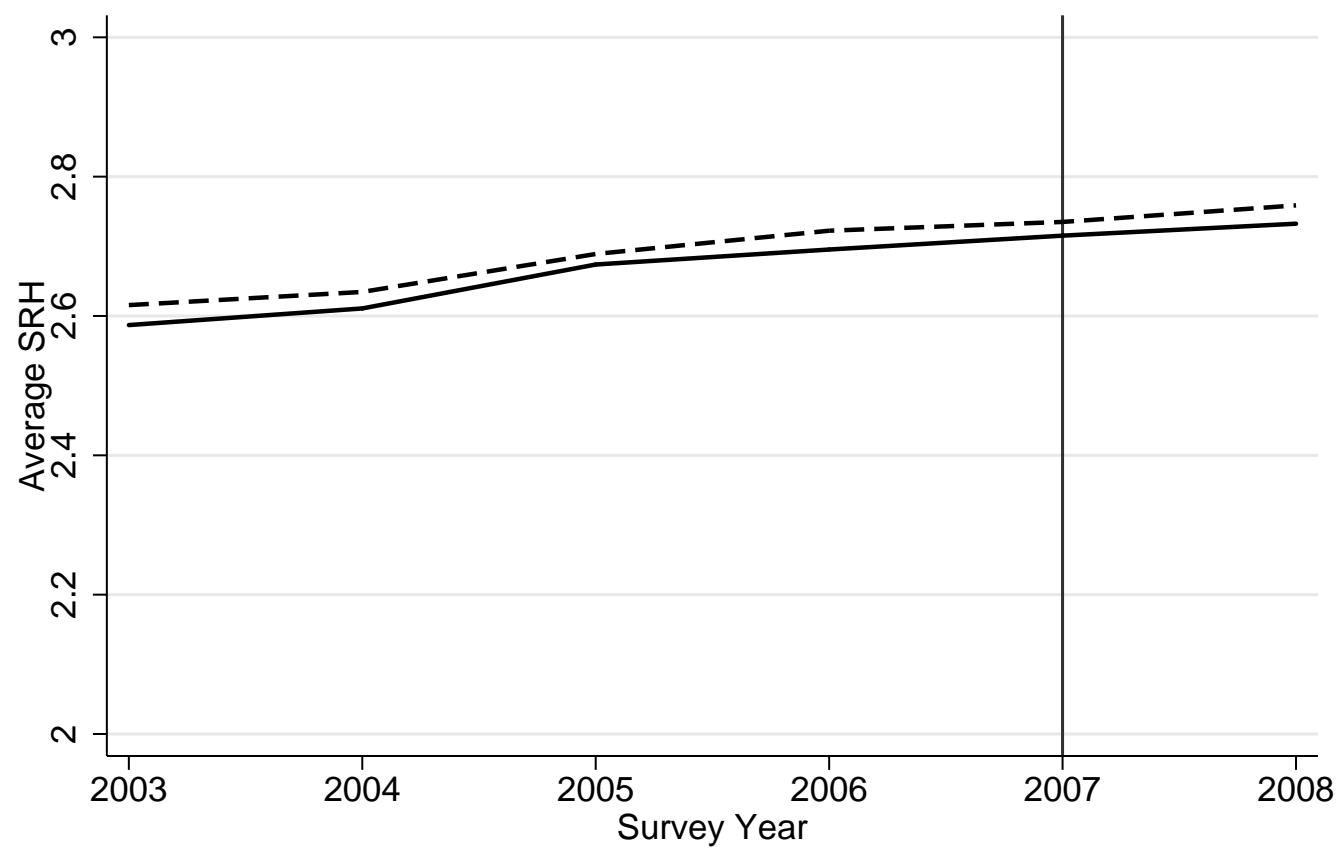

Individuals with ban in 2007 - - Individuals with ban in 2008

Note: Average self-rated health for early-implementing and late-implementing federal states. Individuals with ban in 2007 live in early-implementing states that introduced smoking bans during 2007. Individuals with ban in 2008 live in late-implementing states that introduced smoking bans during 2008. The vertical line indicates the year 2007, when first smoking bans were introduced.

Source: SOEPv28. 
Table 1

Dates of introduction and enforcement of state smoking bans in Germany

\begin{tabular}{|c|c|c|}
\hline Federal state & Date of introduction & $\begin{array}{l}\text { Date of enforcement } \\
\text { (sanctions) }\end{array}$ \\
\hline Baden-Wuerttemberg & August 2007 & August 2007 \\
\hline Bavaria & January 2008 & January 2008 \\
\hline Berlin & January 2008 & July 2008 \\
\hline Brandenburg & January 2008 & July 2008 \\
\hline Bremen & January 2008 & January 2008 \\
\hline Hamburg & January 2008 & January 2008 \\
\hline Hesse & October 2007 & October 2007 \\
\hline Lower Saxony & August 2007 & November 2007 \\
\hline Mecklenburg-West Pomerania & August 2007 & August 2008 \\
\hline North Rhine-Westphalia & January 2008 & January 2008 \\
\hline Rhineland-Palatinate & February 15, 2008 & February 15, 2008 \\
\hline Saarland & February 15, 2008 & June 2008 \\
\hline Saxony & February 2008 & February 2008 \\
\hline Saxony-Anhalt & January 2008 & July 2008 \\
\hline Schleswig-Holstein & January 2008 & January 2008 \\
\hline Thuringia & July 2008 & July 2008 \\
\hline
\end{tabular}

Note: The dates were compiled based on the original state law texts. For all states apart from

Rhineland-Palatinate and Saarland the bans came into effect on the first of the month. For these states, the bans came into affect on the 15th of February. 
Table 2

Descriptive statistics

\begin{tabular}{|c|c|c|c|c|c|c|}
\hline \multirow{3}{*}{$\begin{array}{l}\text { Variable } \\
\text { Self-assessed health }\end{array}$} & \multicolumn{6}{|c|}{ Sample } \\
\hline & \multicolumn{2}{|c|}{ All } & \multicolumn{2}{|c|}{ Non-Smokers } & \multicolumn{2}{|c|}{ Smokers } \\
\hline & 2.716 & 0.946 & 2.738 & 0.951 & 2.679 & 0.935 \\
\hline Smoking ban & 0.458 & 0.498 & 0.456 & 0.498 & 0.461 & 0.499 \\
\hline Year 2008 & 0.481 & 0.500 & 0.481 & 0.500 & 0.482 & 0.500 \\
\hline Day of the year & 87.56 & 50.42 & 86.876 & 50.287 & 88.761 & 50.632 \\
\hline Age & 50.872 & 16.617 & 53.876 & 17.185 & 45.596 & 14.096 \\
\hline Immigrant $(0 / 1)$ & 0.155 & 0.362 & 0.146 & 0.353 & 0.172 & 0.377 \\
\hline Unemployed (0/1) & 0.068 & 0.251 & 0.043 & 0.203 & 0.110 & 0.313 \\
\hline Children $\leqslant 6(0 / 1)$ & 0.104 & 0.305 & 0.098 & 0.297 & 0.113 & 0.317 \\
\hline Children >6 (0/1) & 0.227 & 0.419 & 0.203 & 0.402 & 0.269 & 0.443 \\
\hline Log of household income & 7.703 & 0.540 & 7.723 & 0.529 & 7.666 & 0.556 \\
\hline Log of household size & 0.841 & 0.487 & 0.830 & 0.48 & 0.859 & 0.498 \\
\hline Married (0/1) & 0.650 & 0.477 & 0.687 & 0.464 & 0.586 & 0.493 \\
\hline Divorced (0/1) & 0.084 & 0.278 & 0.060 & 0.238 & 0.126 & 0.332 \\
\hline Widowed (0/1) & 0.072 & 0.259 & 0.090 & 0.286 & 0.041 & 0.198 \\
\hline Education (in years) & 12.005 & 2.568 & 12.176 & 2.684 & 11.704 & 2.320 \\
\hline Female & 0.526 & 0.499 & 0.562 & 0.496 & 0.462 & 0.499 \\
\hline Baden-Wuerttemberg & 0.118 & 0.323 & 0.122 & 0.327 & 0.112 & 0.315 \\
\hline Bavaria & 0.134 & 0.341 & 0.135 & 0.342 & 0.132 & 0.338 \\
\hline Berlin & 0.034 & 0.181 & 0.031 & 0.173 & 0.040 & 0.195 \\
\hline Brandenburg & 0.045 & 0.208 & 0.048 & 0.213 & 0.041 & 0.198 \\
\hline Bremen & 0.007 & 0.085 & 0.007 & 0.086 & 0.007 & 0.083 \\
\hline Hamburg & 0.014 & 0.116 & 0.013 & 0.112 & 0.015 & 0.122 \\
\hline Hesse & 0.064 & 0.245 & 0.062 & 0.240 & 0.069 & 0.253 \\
\hline Lower Saxony & 0.087 & 0.282 & 0.091 & 0.287 & 0.082 & 0.274 \\
\hline Mecklenburg-West Pomerania & 0.025 & 0.156 & 0.025 & 0.157 & 0.025 & 0.155 \\
\hline North Rhine-Westphalia & 0.204 & 0.403 & 0.194 & 0.396 & 0.221 & 0.415 \\
\hline Rhineland-Palatinate & 0.048 & 0.213 & 0.046 & 0.209 & 0.051 & 0.221 \\
\hline Saarland & 0.013 & 0.112 & 0.012 & 0.109 & 0.014 & 0.118 \\
\hline Saxony & 0.082 & 0.275 & 0.090 & 0.286 & 0.069 & 0.253 \\
\hline Saxony-Anhalt & 0.047 & 0.212 & 0.045 & 0.208 & 0.050 & 0.217 \\
\hline Schleswig - Holstein & 0.029 & 0.168 & 0.029 & 0.168 & 0.029 & 0.167 \\
\hline Thuringia & 0.048 & 0.215 & 0.050 & 0.218 & 0.045 & 0.208 \\
\hline Individuals & 15,342 & & 9,772 & & 5570 & \\
\hline Person-year observations & 28,111 & & 17,913 & & 10,198 & \\
\hline
\end{tabular}

Source: SOEPv28, 2007, 2008. 
Table 3

Average self-assessed health before and after smoking ban by state

\begin{tabular}{lcrrr}
\hline State & \multicolumn{2}{c}{ Average self-assessed health } & \multicolumn{2}{c}{$\begin{array}{r}\text { Population } \\
\text { share }\end{array}$} \\
\cline { 2 - 4 } Schleswig-Holstein & Before & After & Change & 0.037 \\
Hamburg & 2.69 & 2.70 & 0.01 & 0.018 \\
Lower Saxony & 2.58 & 2.64 & 0.06 & 0.095 \\
Bremen & 2.71 & 2.69 & -0.02 & 0.011 \\
North Rhine-Westphalia & 2.76 & 2.74 & -0.02 & 0.214 \\
Hesse & 2.75 & 2.73 & -0.02 & 0.075 \\
Rhineland-Palatinate & 2.72 & 2.73 & 0.01 & 0.044 \\
Baden-Württemberg & 2.67 & 2.60 & -0.07 & 0.127 \\
Bavaria & 2.65 & 2.59 & -0.06 & 0.150 \\
Saarland & 2.70 & 2.66 & -0.04 & 0.015 \\
Berlin & 2.80 & 2.79 & -0.01 & 0.043 \\
Brandenburg & 2.77 & 2.82 & 0.05 & 0.031 \\
Mecklenburg-West Pomerania & 2.74 & 2.70 & -0.04 & 0.022 \\
Saxony & 2.72 & 2.64 & -0.08 & 0.058 \\
Saxony-Anhalt & 2.72 & 2.69 & -0.04 & 0.031 \\
Thuringia & 2.74 & 2.76 & 0.02 & 0.029 \\
\hline All states & 2.69 & 2.72 & 0.03 & 1.000 \\
\hline
\end{tabular}

Note: Sample is weighted by SOEP cross-sectional weights.

Source: SOEP 2007, 2008. 
Table 4

Effects of smoking bans

\begin{tabular}{|c|c|c|c|}
\hline & (1) & (2) & (3) \\
\hline & All & Non-smokers & Smokers \\
\hline \multicolumn{4}{|c|}{ Panel A: both genders } \\
\hline \multirow[t]{3}{*}{ All } & -0.053 & -0.097 & 0.029 \\
\hline & $(0.002)^{* * *}$ & $(0.001)^{* * *}$ & $(0.591)$ \\
\hline & {$[0.078]^{*}$} & {$[0.046]^{* *}$} & {$[0.610]$} \\
\hline \multicolumn{4}{|c|}{ Panel B: females } \\
\hline \multirow[t]{3}{*}{ All } & -0.087 & -0.119 & -0.003 \\
\hline & $(0.000)^{* * *}$ & $(0.001)^{* * *}$ & $(0.973)$ \\
\hline & {$[0.081]^{*}$} & {$[0.035]^{* *}$} & {$[0.983]$} \\
\hline \multirow[t]{3}{*}{ Age $<30$} & -0.178 & -0.310 & -0.070 \\
\hline & $(0.096)^{*}$ & $(0.075)^{*}$ & $(0.672)$ \\
\hline & {$[0.087]^{*}$} & {$[0.089]^{*}$} & {$[0.667]$} \\
\hline \multirow[t]{3}{*}{ Age $30-49$} & -0.111 & -0.191 & 0.027 \\
\hline & $(0.024)^{* *}$ & $(0.085)^{*}$ & $(0.703)$ \\
\hline & {$[0.080]^{*}$} & {$[0.094]^{*}$} & [0.648] \\
\hline \multirow[t]{3}{*}{ Age $\geqslant 50$} & -0.038 & -0.051 & 0.027 \\
\hline & $(0.561)$ & $(0.419)$ & $(0.871)$ \\
\hline & {$[0.855]$} & {$[0.709]$} & {$[0.855]$} \\
\hline \multicolumn{4}{|c|}{ Panel C: males } \\
\hline \multirow[t]{3}{*}{ All } & -0.020 & -0.074 & 0.057 \\
\hline & $(0.205)$ & $(0.114)$ & $(0.493)$ \\
\hline & {$[0.317]$} & [0.103] & {$[0.741]$} \\
\hline \multirow[t]{3}{*}{ Age $<30$} & -0.052 & -0.397 & 0.270 \\
\hline & $(0.607)$ & $(0.005)^{* * *}$ & $(0.060)^{*}$ \\
\hline & {$[0.620]$} & {$[0.185]$} & {$[0.300]$} \\
\hline \multirow[t]{3}{*}{ Age $30-49$} & 0.001 & 0.012 & -0.004 \\
\hline & $(0.974)$ & $(0.896)$ & $(0.969)$ \\
\hline & {$[0.985]$} & [0.919] & [0.969] \\
\hline \multirow[t]{3}{*}{ Age $\geqslant 50$} & -0.008 & -0.058 & 0.084 \\
\hline & $(0.856)$ & $(0.288)$ & $(0.455)$ \\
\hline & {$[0.865]$} & {$[0.314]$} & {$[0.581]$} \\
\hline
\end{tabular}

Note: The parameters were estimated separately for each subsample. Cluster-robust p-values are in parentheses. Wild cluster bootstrap-t generated p-values are in brackets. Number of bootstrap replications is 5,000. All estimation models include a piecewise linear time trend, a set of state indicator variables, and a set of standard socio-economic control variables. Significance levels: $*<0.1, *<0.05, * * *<0.01$.

Source: SOEPv28, 2007-2008. 
Table 5

Estimation results: all, smokers, and non-smokers

\begin{tabular}{|c|c|c|c|}
\hline Variable & $\begin{array}{l}(1) \\
\text { All }\end{array}$ & $\begin{array}{c}(2) \\
\text { Non-smokers }\end{array}$ & $\begin{array}{c}(3) \\
\text { Smokers }\end{array}$ \\
\hline \multirow[t]{2}{*}{ Ban indicator $(0 / 1)$} & $-0.053 * * *$ & $-0.097 * * *$ & 0.029 \\
\hline & $(0.014)$ & $(0.023)$ & $(0.052)$ \\
\hline \multirow[t]{2}{*}{ Year $(0 / 1)$} & 0.018 & 0.040 & -0.025 \\
\hline & $(0.018)$ & $(0.026)$ & $(0.058)$ \\
\hline \multirow[t]{2}{*}{ Day of year } & -0.000 & 0.000 & -0.000 \\
\hline & $(0.000)$ & $(0.000)$ & $(0.000)$ \\
\hline \multirow[t]{2}{*}{ Year $\times$ day of year } & $0.000 *$ & $0.001 * *$ & -0.000 \\
\hline & $(0.000)$ & $(0.000)$ & $(0.000)$ \\
\hline \multirow[t]{2}{*}{ Age } & $0.027 * * *$ & $0.021 * * *$ & $0.041 * * *$ \\
\hline & $(0.004)$ & $(0.005)$ & $(0.008)$ \\
\hline \multirow[t]{2}{*}{ Age squared/100 } & -0.005 & 0.001 & $-0.020 * *$ \\
\hline & $(0.004)$ & $(0.004)$ & $(0.008)$ \\
\hline \multirow[t]{2}{*}{ Immigrant $(0 / 1)$} & 0.005 & 0.032 & -0.033 \\
\hline & $(0.020)$ & $(0.027)$ & $(0.030)$ \\
\hline \multirow[t]{2}{*}{ Unemployed $(0 / 1)$} & $0.153 * * *$ & $0.174 * * *$ & $0.115^{* *}$ \\
\hline & $(0.045)$ & $(0.054)$ & $(0.051)$ \\
\hline \multirow[t]{2}{*}{ Children $\leqslant 6(0 / 1)$} & -0.032 & -0.025 & -0.040 \\
\hline & $(0.027)$ & $(0.027)$ & $(0.056)$ \\
\hline \multirow[t]{2}{*}{ Children >6 (0/1) } & $-0.037 *$ & $-0.054 *$ & -0.032 \\
\hline & $(0.019)$ & $(0.026)$ & $(0.023)$ \\
\hline \multirow[t]{2}{*}{ Log of household income } & $-0.195 * * *$ & $-0.186 * * *$ & $-0.215^{* * *}$ \\
\hline & $(0.015)$ & $(0.019)$ & $(0.034)$ \\
\hline \multirow[t]{2}{*}{ Log of household size } & $0.056^{*}$ & $0.066 * *$ & 0.063 \\
\hline & $(0.027)$ & $(0.030)$ & $(0.054)$ \\
\hline \multirow[t]{2}{*}{ Married (0/1) } & 0.015 & 0.023 & 0.006 \\
\hline & $(0.026)$ & $(0.031)$ & $(0.034)$ \\
\hline \multirow[t]{2}{*}{ Divorced $(0 / 1)$} & 0.018 & $0.081 *$ & $-0.077 *$ \\
\hline & $(0.023)$ & $(0.041)$ & $(0.042)$ \\
\hline \multirow[t]{2}{*}{ Widowed (0/1) } & -0.017 & -0.017 & 0.012 \\
\hline & $(0.028)$ & $(0.041)$ & $(0.062)$ \\
\hline \multirow[t]{2}{*}{ Education (in years) } & $-0.030 * * *$ & $-0.027 * * *$ & $-0.031 * * *$ \\
\hline & $(0.003)$ & $(0.004)$ & $(0.005)$ \\
\hline \multirow[t]{2}{*}{ Constant } & $3.266 * * *$ & $3.235 * * *$ & $3.151 * * *$ \\
\hline & $(0.171)$ & $(0.159)$ & $(0.260)$ \\
\hline State fixed effects & included & included & included \\
\hline Person-year observations & 28,111 & 17,913 & 10,198 \\
\hline
\end{tabular}

Note: Results from ordinary least squares estimations with cluster-robust standard errors in parentheses. Significance levels: $*<0.1, *<0.05, * * *<0.01$.

Source: SOEP v28, 2007, 2008. 
Table 6

Extension: introduction versus enforcement

\begin{tabular}{lrrr}
\hline & $(1)$ & $(2)$ & $(3)$ \\
& All & Non-smokers & Smokers \\
\hline Introduction & -0.033 & $-0.089 * *$ & 0.071 \\
Enforcement & $(0.025)$ & $(0.034)$ & $(0.061)$ \\
& -0.025 & -0.010 & -0.054 \\
& $(0.025)$ & $(0.030)$ & $(0.038)$ \\
\hline
\end{tabular}

Note: The parameters were estimated separately for each subsample. Cluster-robust standard errors are in parentheses. All estimation models include a piecewise linear time trend and a set of standard socio-economic control variables. Significance levels: $*<0.1, *<0.05, * * *<0.01$.

Source: SOEPv28, 2007-2008. 
Table 7

Robustness

(1)

(2)

(3)

(4)

(5)

\begin{tabular}{|c|c|c|c|c|c|}
\hline Sample & $\begin{array}{l}\text { piecewise } \\
\text { linear }\end{array}$ & $\begin{array}{l}\text { fully non- } \\
\text { parametric }\end{array}$ & $\begin{array}{l}\text { (1) plus state } \\
\text { specific trend }\end{array}$ & $\begin{array}{l}\text { (2) plus state } \\
\text { specific trend }\end{array}$ & $\begin{array}{c}\text { placebo } \\
\text { ban }\end{array}$ \\
\hline \multicolumn{6}{|c|}{ Panel A: both genders } \\
\hline \multirow{3}{*}{ 1. All } & -0.053 & -0.048 & -0.051 & -0.041 & 0.004 \\
\hline & $(0.002)^{* * *}$ & $(0.027)^{* *}$ & $(0.012)^{* *}$ & $(0.060)^{*}$ & $(0.824)$ \\
\hline & {$[0.078]^{*}$} & {$[0.365]$} & {$[0.154]$} & {$[0.412]$} & {$[0.843]$} \\
\hline \multirow[t]{3}{*}{ 2. Non-smokers } & -0.097 & -0.082 & -0.096 & -0.078 & 0.020 \\
\hline & $(0.001)^{* * *}$ & $(0.004)^{* * *}$ & $(0.005)^{* * *}$ & $(0.003)^{* * *}$ & $(0.243)$ \\
\hline & {$[0.046]^{* *}$} & {$[0.096]^{*}$} & {$[0.049]^{* *}$} & {$[0.082]^{*}$} & {$[0.359]$} \\
\hline \multirow[t]{3}{*}{ 3. Smokers } & 0.029 & 0.005 & 0.035 & 0.013 & -0.023 \\
\hline & $(0.591)$ & $(0.897)$ & $(0.569)$ & $(0.787)$ & $(0.312)$ \\
\hline & {$[0.610]$} & {$[0.901]$} & {$[0.574]$} & [0.809] & {$[0.293]$} \\
\hline \multicolumn{6}{|l|}{ Panel B: females } \\
\hline \multirow[t]{3}{*}{ 4. All } & -0.087 & -0.066 & -0.097 & -0.069 & 0.011 \\
\hline & $(0.000)^{* * *}$ & $(0.061)^{*}$ & $(0.000)^{* * *}$ & $(0.059)^{*}$ & $(0.664)$ \\
\hline & {$[0.081]^{*}$} & {$[0.373]$} & {$[0.102]$} & {$[0.374]$} & {$[0.695]$} \\
\hline \multirow[t]{3}{*}{ 5. Non-smokers } & -0.119 & -0.091 & -0.129 & -0.086 & 0.008 \\
\hline & $(0.001)^{* * *}$ & $(0.001)^{* * *}$ & $(0.006)^{* * *}$ & $(0.004)^{* * *}$ & $(0.773)$ \\
\hline & {$[0.035]^{* *}$} & {$[0.070]^{*}$} & {$[0.056]^{*}$} & {$[0.087]^{*}$} & [0.799] \\
\hline \multirow[t]{3}{*}{ 6. Smokers } & -0.003 & -0.043 & -0.013 & -0.062 & 0.017 \\
\hline & $(0.973)$ & $(0.595)$ & $(0.898)$ & $(0.494)$ & $(0.615)$ \\
\hline & {$[0.983]$} & {$[0.649]$} & {$[0.944]$} & {$[0.559]$} & {$[0.667]$} \\
\hline \multicolumn{6}{|l|}{ Panel C: males } \\
\hline \multirow[t]{3}{*}{ 7. All } & -0.020 & -0.033 & -0.006 & -0.017 & -0.005 \\
\hline & $(0.205)$ & $(0.144)$ & $(0.804)$ & $(0.544)$ & $(0.771)$ \\
\hline & {$[0.317]$} & {$[0.290]$} & {$[0.830]$} & {$[0.743]$} & {$[0.760]$} \\
\hline \multirow[t]{3}{*}{ 8. Non-smokers } & -0.074 & -0.082 & -0.056 & -0.070 & 0.036 \\
\hline & $(0.114)$ & $(0.099)^{*}$ & $(0.074)^{*}$ & $(0.037)^{* *}$ & $(0.135)$ \\
\hline & [0.103] & {$[0.175]$} & {$[0.084]^{*}$} & {$[0.160]$} & {$[0.210]$} \\
\hline \multirow[t]{3}{*}{ 9. Smokers } & 0.057 & 0.073 & 0.066 & 0.089 & -0.058 \\
\hline & $(0.493)$ & $(0.432)$ & $(0.489)$ & $(0.460)$ & $(0.079)^{*}$ \\
\hline & {$[0.741]$} & {$[0.486]$} & {$[0.652]$} & {$[0.546]$} & {$[0.066]^{*}$} \\
\hline
\end{tabular}

Note: The parameters were estimated separately for each subsample. Cluster-robust p-values are in parentheses. Wild cluster bootstrap-t generated p-values are in brackets. Number of bootstrap replications is 5,000. Col. (1) (4) show results for models with different specifications of the time trend and use data from 2007 and 2008 . Col. (5) applies a piecewise linear time trend and uses data from 2005 and 2006. All estimation models include a set of state indicator variables and standard socio-economic control variables. Significance levels: $*<0.1, *<0.05$, $* * *<0.01$.

Source: SOEPv28, 2005-2008. 


\section{A Appendix}

Table A1

Sample size by subgroups

(1)

(2)

(3)

All

Non-smokers

Smokers

\begin{tabular}{lrrr}
\hline $\begin{array}{l}\text { Panel A } \\
\text { All }\end{array}$ & 28,111 & 17,913 & 10,198 \\
\hline Panel B & & & \\
Females & 14,779 & 10,075 & 4,704 \\
Age $<30$ & 1,703 & 937 & 766 \\
Age 30-49 & 5,686 & 3,348 & 2,338 \\
Age $\geqslant 50$ & 7,390 & 5,790 & 1,600 \\
\hline Panel C & & & 5,494 \\
Males & 13,322 & 7,838 & 713 \\
Age $<30$ & 1,442 & 729 & 2,600 \\
Age 30-49 & 5,186 & 2,586 & 2,181 \\
Age $\geqslant 50$ & 6,704 & 4,523 & \\
\hline Note: Number of person-year observations & & &
\end{tabular}

Note: Number of person-year observations.

Source: SOEPv28, 2007-2008. 
Table A2

Alternative estimation method: ordered probit

\begin{tabular}{|c|c|c|c|}
\hline Variable & $\begin{array}{l}(1) \\
\text { All }\end{array}$ & $\begin{array}{c}(2) \\
\text { Non-smokers }\end{array}$ & $\begin{array}{c}(3) \\
\text { Smokers }\end{array}$ \\
\hline Ban indicator $(0 / 1)$ & $\begin{array}{l}-0.068 * * * \\
(0.016)\end{array}$ & $\begin{array}{l}-0.127 * * * \\
(0.036)\end{array}$ & $\begin{array}{r}0.037 \\
(0.059)\end{array}$ \\
\hline Year & $\begin{array}{r}0.017 \\
(0.019)\end{array}$ & $\begin{array}{r}0.045 \\
(0.037)\end{array}$ & $\begin{array}{r}-0.035 \\
(0.065)\end{array}$ \\
\hline Day of year $(0 / 1)$ & $\begin{array}{l}-0.000 \\
(0.000)\end{array}$ & $\begin{array}{r}0.000 \\
(0.000)\end{array}$ & $\begin{array}{r}-0.000 \\
(0.000)\end{array}$ \\
\hline Year $\times$ day of year & $\begin{array}{l}0.000 * * * \\
(0.000)\end{array}$ & $\begin{array}{l}0.001 * * * \\
(0.000)\end{array}$ & $\begin{array}{r}-0.000 \\
(0.000)\end{array}$ \\
\hline Age & $\begin{array}{l}0.040 * * * \\
(0.006)\end{array}$ & $\begin{array}{l}0.034 * * * \\
(0.007)\end{array}$ & $\begin{array}{l}0.056^{* * * *} \\
(0.010)\end{array}$ \\
\hline Age squared/100 & $\begin{array}{l}-0.013 * * * \\
(0.005)\end{array}$ & $\begin{array}{r}-0.005 \\
(0.006)\end{array}$ & $\begin{array}{l}-0.030 * * * \\
(0.010)\end{array}$ \\
\hline Immigrant $(0 / 1)$ & $\begin{array}{l}-0.003 \\
(0.025)\end{array}$ & $\begin{array}{r}0.030 \\
(0.034)\end{array}$ & $\begin{array}{r}-0.047 \\
(0.037)\end{array}$ \\
\hline Unemployed $(0 / 1)$ & $\begin{array}{l}0.187 * * * \\
(0.053)\end{array}$ & $\begin{array}{l}0.218 * * * \\
(0.065)\end{array}$ & $\begin{array}{l}0.133^{* *} \\
(0.062)\end{array}$ \\
\hline Children $\leqslant 6(0 / 1)$ & $\begin{array}{r}-0.034 \\
(0.036)\end{array}$ & $\begin{array}{r}-0.027 \\
(0.038)\end{array}$ & $\begin{array}{r}-0.041 \\
(0.072)\end{array}$ \\
\hline Children > $6(0 / 1)$ & $\begin{array}{l}-0.040 \\
(0.025)\end{array}$ & $\begin{array}{l}-0.065^{*} \\
(0.036)\end{array}$ & $\begin{array}{l}-0.028 \\
(0.030)\end{array}$ \\
\hline Log of household income & $\begin{array}{l}-0.241 * * * \\
(0.019)\end{array}$ & $\begin{array}{l}-0.237 * * * \\
(0.024)\end{array}$ & $\begin{array}{l}-0.254 * * * \\
(0.042)\end{array}$ \\
\hline Log of household size & $\begin{array}{c}0.065^{*} \\
(0.035)\end{array}$ & $\begin{array}{l}0.082 * * \\
(0.042)\end{array}$ & $\begin{array}{r}0.068 \\
(0.066)\end{array}$ \\
\hline Married (0/1) & $\begin{array}{r}0.029 \\
(0.033)\end{array}$ & $\begin{array}{r}0.040 \\
(0.042)\end{array}$ & $\begin{array}{r}0.016 \\
(0.042)\end{array}$ \\
\hline Divorced $(0 / 1)$ & $\begin{array}{r}0.021 \\
(0.028)\end{array}$ & $\begin{array}{l}0.103 * * \\
(0.051)\end{array}$ & $\begin{array}{l}-0.095 * \\
(0.050)\end{array}$ \\
\hline Widowed (0/1) & $\begin{array}{l}-0.017 \\
(0.033)\end{array}$ & $\begin{array}{l}-0.012 \\
(0.049)\end{array}$ & $\begin{array}{r}0.009 \\
(0.069)\end{array}$ \\
\hline Education (in years) & $\begin{array}{l}-0.039 * * * \\
(0.004)\end{array}$ & $\begin{array}{l}-0.035 * * * \\
(0.005)\end{array}$ & $\begin{array}{l}-0.038 * * * \\
(0.007)\end{array}$ \\
\hline State fixed effects & included & included & included \\
\hline cut1 & $\begin{array}{r}-2.213 \\
(0.231)\end{array}$ & $\begin{array}{l}-2.202 \\
(0.219)\end{array}$ & $\begin{array}{r}-2.013 \\
(0.338)\end{array}$ \\
\hline cut 2 & $\begin{array}{r}-0.653 \\
(0.234)\end{array}$ & $\begin{array}{r}-0.619 \\
(0.221)\end{array}$ & $\begin{array}{r}-0.474 \\
(0.343)\end{array}$ \\
\hline cut3 & $\begin{array}{r}0.454 \\
(0.235)\end{array}$ & $\begin{array}{r}0.505 \\
(0.226)\end{array}$ & $\begin{array}{r}0.611 \\
(0.340)\end{array}$ \\
\hline cut4 & $\begin{array}{r}1.414 \\
(0.231)\end{array}$ & $\begin{array}{r}1.499 \\
(0.226)\end{array}$ & $\begin{array}{r}1.515 \\
(0.326)\end{array}$ \\
\hline Person-year observations & 28,111 & 17,913 & 10,198 \\
\hline
\end{tabular}

Note: Cluster-robust standard errors in parentheses. Significance levels: $*<0.1, *<0.05, * * *<0.01$. Source: SOEP v28, 2007, 2008. 